\title{
An Assessment of Residential Quality of Life in Informal Settlements in Port Harcourt Municipality
}

\author{
${ }^{1}$ Ebiwari Wokekoro, ${ }^{2}$ Opuenebo Binya Owei \\ ${ }^{1}$ Dept of Estate Management, \\ ${ }^{2}$ Dept of Urban and Regional Planning, Rivers State University of Science and Technology PMB 5080, Port \\ Harcourt.
}

\begin{abstract}
This study has assessed urban residential quality of life in two neighbourhoods of Port Harcourt, Rivers State, Nigeria -- drawn from the informal (waterfront) settlements that line the creeks of the city. The study set out to ascertain residents' perception of neighbourhood attributes, residential quality of life as whole and the variables considered by residents to be the most important to enhance residential quality of life. Neighbourhood attributes were studied in situ without experimental manipulation and at one period in time, i.e. the study adopted a passiveobservational research design. The study utilized both secondary and primary data sources. Primary data was collected using face-to-face administration of a largely pre-coded household questionnaire, to a probability sample of 192 respondents, drawn from the 2 neighbourhoods. Data analysis was based on responses from 191 questionnaires retrieved and the univariate analytical method was adopted. The study found, that residential quality of life in the informal settlement of Port Harcourt Municipality was low with garbage in the neighbourhoods. There was no street lighting in the neighbourhoods, periodic flooding occurring in two the neighbourhoods. The study further revealed that $28.8 \%$ of the residents in these neighbourhoods were unhappy with their residential quality of life and 52.9\% of the residents perceived their neighbourhoods to be of medium quality. A key conclusion of the study was that the improvement of neighbourhood residential conditions as perceived by the residents was important in raising residential quality of life, and recommendations included that in the provision of public infrastructure and services, the perceptions and preferences of the beneficiaries/target population must be taken into account to achieve user satisfaction.
\end{abstract}

\section{Introduction}

The concept, Quality of Life, encompasses the basic conditions of life, including adequate food, shelter, and safety, as well as "life enrichers", which are based on the individual's values, beliefs, needs and interests (WHO-IACCID, 2000). Measuring quality of life means that we value quality within people's lives and that we want to maintain and/or enhance the things that already, or could, add quality to people's lives. It also infers that we want to take action to improve the things that currently detract from quality of people's lives (WHO-IACCID, 2000).

The search for quality of life, particularly in the city, has occupied post-industrial and predominantly urbanized societies (such as the United States of America and Great Britain) for more than 40 years. This has led to initiatives to measure the concept in urban areas (Senecal, 2002) who argued that, the concept of quality of life, as applied to the urban environment, is usually understood in two ways. The first concerns the living environment and involves the patterns of advantages, disadvantages and opportunities that affect each citizen through accessibility to services, facilities and amenities. Other elements of the living environment include economic vitality and social equity, which encapsulate an infinite number of specific issues, notably, the quality and affordability of housing. The second approach relates to the natural environment in urban spaces. This approach holds that such factors as air, water, soil quality; and the amount of available green space affect the ways we live (Senecal, 2002).

Senecal (2002) added that other aspects that may be used to identify quality of life include aesthetic value, satisfaction with one's home, and patterns of governance and there are also issues of perception that take into account people's experiences in the city, the routes they travel, and the sensory quality of their surroundings.

Nowadays, cities have become the target of quality of life measurement since they exhibit contemporary culture, ranging from technological development to social progress. Indeed, the process of urban planning and management is aimed at raising quality of life, especially with regard to improvement of facilities and services that fulfil socio-economic needs such as education, health, housing, entertainment, and safety (Discoli, et. al., 2006). 
An Assessment of Residential Quality of Life in Informal Settlements in Port Harcourt Municipality

Port Harcourt, one of Nigeria's major cities, has been experiencing rapid urbanization since its inception in 1913. The city has grown from 5,000 persons in 1915, two years after its inception, to 79,634 in 1953, and to 179,563 in 1963,(Ogionwo,1979). The 1991 census gave the city's population as 440,399 and the 2006 census fixed it at 541115. The population was projected from the census figure of 2006 to a projected population of 963,373 in 2010 assuming linear growth and an average annual growth rate of 5.2\%. This level of population growth has meant considerable spatial expansion, which has engulfed once distant villages on the urban periphery, to the extent that they can no longer be distinguished but have become part of the urban fabric (Wokekoro and Owei, 2006).

Urban infrastructure and services have failed to keep pace with this growth. In addition to rising urban poverty, there is a worsening of urban environmental problems. Such challenges as poor solid waste management, uncontrolled housing and neighbourhood development, flooding, traffic congestion, poor state of the urban physical environment and rising crime rates have been documented (Ugwuorah, 2002; Mchi, 1997). More recently, Obinna, Owei and Mark (2010) have also noted the deplorable housing, inadequate space, and absence of basic services in the informal settlements of the city.

This state of affairs triggered the desire to measure residential quality of life in the informal settlements in Port Harcourt Municipality both objectively and subjectively. The aim was to demonstrate the nature and magnitude of deficient conditions in these parts of the municipality and propose appropriate measures to deal with them.

It is pertinent to note here that objective conditions or indicators "typically involve reports made by people who are not characterizing themselves" (Andrews, 1980); while subjective indicators refer to people's perceptions or evaluations of aspects of their lives, for example, housing (Andrews, 1980).

Spatially, the study covers informal settlements in Port Harcourt Municipality; that is, Port Harcourt Local Government Area (PHALGA). The two informal settlements studied are Marine- Base Waterfront and Afikpo Waterfront settlements.

\subsection{Goal and Objectives of the Study}

The goal of this study is to assess residents' perception of residential quality of life in the informal settlements in Port Harcourt Municipality, with a view to proffering policy measures for improvement.

The objectives of the study are to:

(i) ascertain residents' perceptions of neighbourhood attributes;

(ii) ascertain residents' perceptions of residential quality of life.

(iii) obtain Perceived Neighbourhood Quality Index (PNQI)

(iv) ascertain the variables that are most important to residents in improving residential quality of life in Port Harcourt.

\subsection{Background Information about the Study Area}

Port Harcourt, capital city of Rivers State, Nigeria, lies $40 \mathrm{~km}$ up the mouth of the Bonny River, in the Niger Delta. Originally known as "Igwu-Ocha" by the indigenous Ikwerre, was founded in 1913 by the British in an area traditionally inhabited by the Ikwerre and the Okrika Ijaw. It was named after Viscount Harcourt, then British Secretary of State for the Colonies. The initial purpose of the port was to export the coal, which geologist Albert Ernest Kitson had discovered in Enugu in 1912 (Ogionwo, 1979).

It is one of Nigeria's fastest growing cities. The average annual growth rate of Port Harcourt between 1963 and 2010 has been computed to be 5.2\%. The growth of Port Harcourt is tied to the social and economic history of the country. Figure 1 is a map of Port Harcourt Municipality showing the study locations.

The city is a major educational, administrative, and industrial centre, and is regarded as the oil capital of Nigeria, since it hosts most of the nation's multi-national oil and gas exploration and production companies, two refineries, petroleum-related service companies, as well as a fast expanding commercial sub-sector (Wokekoro and Owei, 2006).

Squatter settlements originated in Port Harcourt in the 1970s, after the end of the Nigerian civil war (19671970). According to Ibeakuzie and Jaja (2003) the reasons for the growth of these squatter settlements are twofold: firstly, the high cost of urban land in the city is obviously beyond the reach of the urban poor and, secondly, the proximity of the lands to the city centre and informal employment centres.

According to a field survey on waterfront squatter settlements in Port Harcourt in 1993, there were fortynine (49) such settlements around Port Harcourt with a combined estimated population of 263,300, representing $64.7 \%$ of the total population of Port Harcourt which the 1991 census put at 440,399 (Ibeakuzie and Jaja, 2003). See the location of the squatter settlements in Figure 2. 
Squatter settlements play a vital role in providing residential accommodation for mostly low income groups in Port Harcourt. As a result of the large population of low-income earners in Port Harcourt City, more of such settlements are developing in spite of their poor environmental conditions and other adverse socio-economic circumstances (Ibeakuzie and Jaja, 2003). (See Plate 1 for a typical view of a squatter settlement).

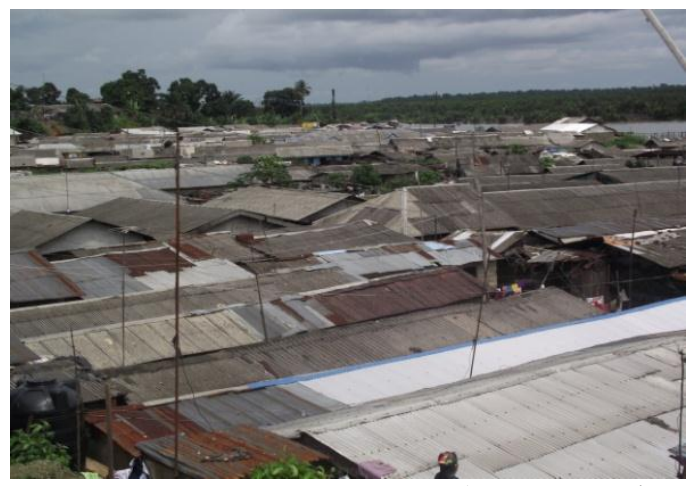

Plate 1 : A typical View of an Informal Settlement. (Source: Author's Field Survey, 2011)

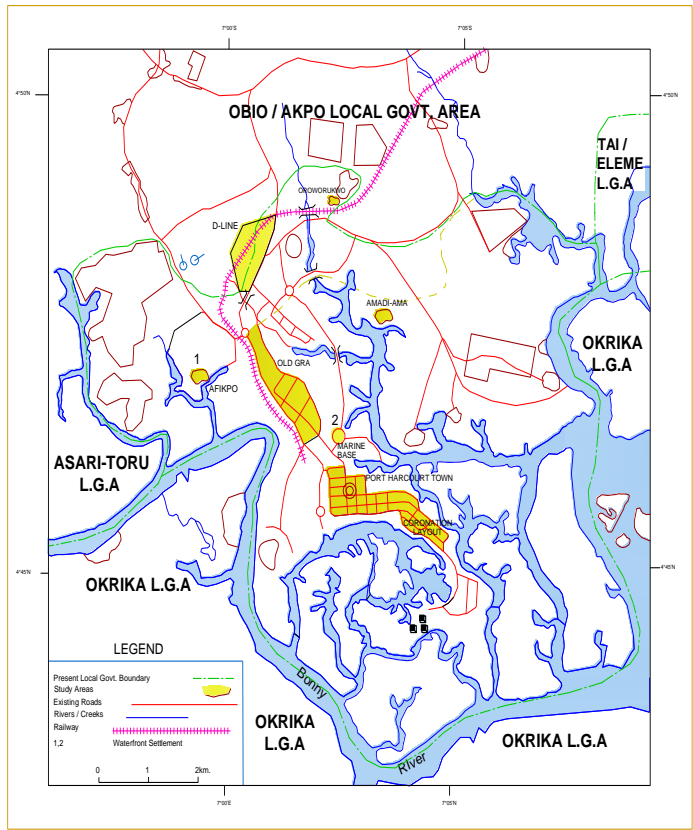

Figure 1: Port Harcourt Municipality Showing the Study Area 


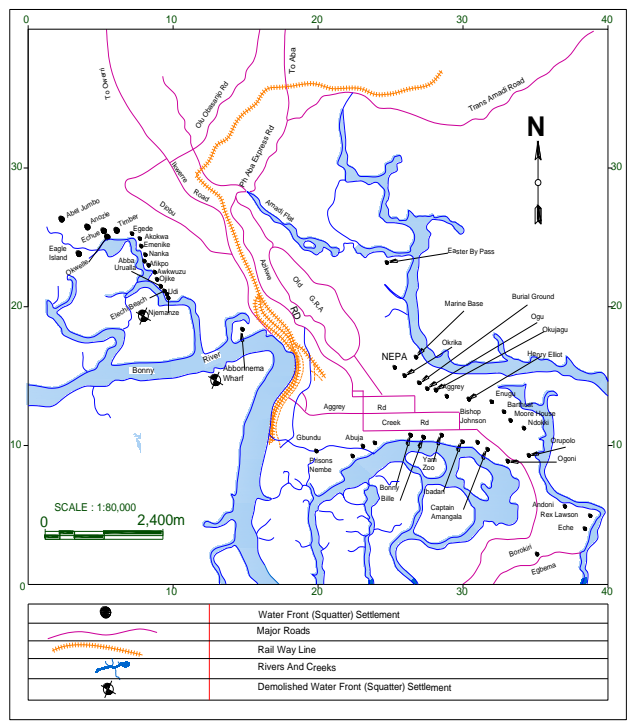

Figure 2: Port Harcourt, Showing Distribution of Waterfront (Squatter) Settlements

(Source: Author's Field Survey, 2011)

\section{Review Of Relevant Literature}

The meaning of the phrase "urban quality of life" differs a good deal as it is variously used but, in general, it is intended to refer to either the conditions of the environment in which people live (air and water pollution, or poor housing, for example), or to some attribute of people themselves (such as health or educational achievement) (Pacione, 2003).

Lotfi and Solaimani (2009) stated that a number of researchers have reviewed literature on Quality of Life (QOL) and there is general agreement that a meaningful definition of QOL must recognize that there are two linked dimensions to the concept, namely a psychological one and an environmental one.),

There are two sets of indicators for measuring quality of life with which most of the researchers are agreed. The first set comprises objective indicators which refer to the objective and visible aspects of urban life and are defined by different elements, for example the number of hospitals in a city, unemployment rate, the volume of crime and the area of urban green spaces. The second set comprises subjective indicators which try to measure and quantify the citizens' satisfaction with those objective attributes ( Lotfi and Solaimani,2009).

QOL is concerned with people's welfare. It is defined as something that makes life better. (Discoli et. al., 2006). A number of domains of QOL (well-being) have been identified in the international quality of life literature. For example, University of Oklahoma School of Social Work (www.gdrc.org) identifies the following:

Family and Friends;

Work;

Neighbourhood/Shelter;

Community;

Health;

Education; and

Spiritual.

Each domain contributes to one's overall assessment of the QOL as a whole. The focus here is on the residential environment or what is referred to above as Neighbourhood/Shelter. Various researchers have addressed this dimension.

\subsection{Research on Residential Quality of Life}

Giannais (1996) used a structural approach to hedonic equilibrium model to obtain a quality of life ranking of six cities in Southern Ontario, Canada namely: Guelph, Kitchener, London, Sarnia, St. Catharine, and Windsor and found that residential quality of life is a function of housing and neighbourhood characteristics (number of rooms, age of the house, crime rate, air quality, and mean annual temperature). The model was estimated using 
An Assessment of Residential Quality of Life in Informal Settlements in Port Harcourt Municipality

census tract data for the six cities. The study revealed that each of the six cities provides a different QOL distribution to its residents.

Pacione (2003) reported that in urban social geography, considerable effort has been directed to assessing the quality of different residential environments. Pacione (2003) in his paper explains the social geographical approach to research into QOL and urban environmental quality. A five-dimensional model for QOL research is presented, and a number of key conceptual and methodological issues were examined. Two case studies were employed to illustrate the application of the five-dimensional social geographical perspective in a real world context. The first case study of social geographical research in the field of QOL studies is selected to illustrate the use of objective territorial social indicators to examine differential QOL in the city of Glasgow. In his research, particular attention was focused on conditions at the disadvantaged end of the quality of life spectrum.

A combination of statistical and cartographic analysis was employed to identify the nature, intensity and incidence of multiple deprivations in the city. A set of 64 indicators relating to demographic, social, economic and residential conditions was extracted from the national census for each of the 5374 output areas in Glasgow. The data set was subjected first to univariate analysis to examine the distributions of individual social indicators across the city.

An R-type principal components analysis was used to explore the weave of linkages among the individual distributions, and to provide a conceptually and statistically rigorous composite measure of multiple deprivations. The study indicates that principal components were readily identified as indicators of multiple deprivations. Calculation of component scores provided a measure of deprivation for each of the 5,374 census output areas in the city. Mapping these scores revealed the spatial expression of multiple deprivations in Glasgow. This research identified the nature, intensity and incidence of multiple deprivations within the city. In addition, identification of the major loci of deprivation provided a basis for subsequent detailed analyses of particular problems and problem areas. The results also provided a basis for critical assessment of policies aimed at alleviating conditions of disadvantage, as well as a framework for future policy formulation.

The second example of the urban social geography approach to quality of life illustrates the use of subjective social indicators to gauge gender-differentiated fear of crime at the local level within Glasgow. His research was designed to gauge the nature and extent of fear of crime among male and female residents of a deprived social housing estate on the edge of Glasgow, and to identify the geography of fear within the area.

The research employed an interview procedure to determine the relative importance of crime as a social problem on the estate. For both males and females crime was regarded as the second most serious problem in the area. Related social problems were identified in references to the general unfriendliness of the locality and bad relations between residents and the police. Assault and burglary were the most prevalent crimes reported. Investigation of the fear of crime revealed clear gender-based differences. For most young males the high risk of assault was an accepted part of their lifestyle and living environment. Respondents accepted that they are 'fair game' and an automatic target for local gangs. The relative physical weakness of young females fostered a fear of assault and in particular sexual assault. These perceptions of risk conditioned the daily activity patterns of people living on the estate.

Detailed information was also sought on respondents' cognitive maps of fear in order to identify specific danger areas within the estate. Further, analysis of the characteristics of these dangerous spaces can contribute to the design of policies aimed at reducing fear of crime in the locality.

Camfield (2005) conducted a study on how different people characterize quality of life in 24 rural, periurban and urban sites in Bangladesh, Ethiopia, Thailand and Peru and found out that the basic ingredients of a good life are very similar, such as having a partner, a family (and a support network that extends beyond it), a good home, a pleasant environment and enough money or other resources to meet the daily needs of the family. Camfield (2005) also reported that the main priorities for people from Bangladesh are maintaining family harmony, getting salaried employment, and being educated, while for people in Ethiopia they are having your own home, enough to eat and drink and being respected by your neighhbours. Camfield also added that the greatest differences are not between people from different countries but between men and women of different ages whose different identities or experiences cause them to value different things. For example, in Thailand, the older generation wanted to be healthy and able to attend the temple, while the young men wanted good jobs and motorbikes.

Hall, et.al.(2008) considered valuation of amenities in urban neighborhoods and satisfaction with both those neighborhoods and life in general. First, rents were used to estimate neighborhood amenities price in San Jose, which explained 39 percent of the standardized variation in rents. Some districts ranked very high in housing characteristics but poorly in neighborhood amenities, while others ranked poorly in housing characteristics but high 
An Assessment of Residential Quality of Life in Informal Settlements in Port Harcourt Municipality

in neighborhood amenities, suggesting that policy measures might reduce inequality in urban areas through improving neighborhood amenities.

Second, the paper explored differences in the valuation of amenities by calculating prices in different urban areas. In more sparsely populated urban areas, distance to national parks was less important, but distance to primary roads became more important. Finally, housing and safety satisfaction represented the key components of life satisfaction.

Coker, et al. (2007) carried out a survey of housing quality and neighbourhood environments in Ibadan City, Nigeria. The study evaluated the housing infrastructure and identified those areas where there was a likelihood of future incidences of disease and epidemics. Based on existing demographic and land use characteristics, the city could be divided into high, medium and low-density zones. Penalty scoring, rather than positive scoring, was used to assess the conditions and quality of houses and the neighbourhood environment in each of the zones. Houses in the high-density area had the worst property and environmental characteristics followed by houses in the mediumdensity area. Based on housing condition alone, approximately half of all the dwellings surveyed $(n=172)$ in the three zones were categorised as either substandard or unfit for human habitation. Based on neighbourhood environment, none of the high and medium-density housing areas and only one of the low density areas attained the good-scoring grade. This is attributed in part to the many residents who are polygamists. The houses are overcrowded with perhaps up to eight persons per room and to tenant abuse by internal conversion to increase the occupancy rate. More than half of the houses surveyed have at least or more major defect. Recommendations include government directed infrastructure improvements; a regeneration-drive by private investors with possible displacement of residents from the high-density zone to new towns; a vigorous programme of housing and health education; enhanced collaboration between stakeholders to develop enforceable standards for existing housing stock and future builds.

Salau (1986) examines the variations in the quality of life at the relatively neglected inter-urban scale in a developing nation. Based on a sample survey of 3,800 heads of households in Nigeria cities ranked into three categories: large, medium and small, the study found that level of living is related to city size, with the residents of large cities having a higher quality of life than those in the medium and small cities.

Guhathakurta and Sadalla (undated) stated that the contributions of water supply to the quality of life sector are straightforward. They reported that when the gap between demand and supply for water increases, there is a corresponding decrease in perceived quality of life. Alternatively, a decrease in the demand-supply gap for water improves quality of life perception.

\section{Research Method}

The target population is composed of household members residing in the neighbourhoods of the four study strata. This study adopted the stratified multistage sampling technique (Kish, 1965). The sampling stages are given below:

Stage 1: Selection of neighbourhoods/communities from the informal settlements (see selected communities in Table 1.

Stage 2: Listing of buildings and households from the selected neighbourhood/communities

Stage 3: Selection of households to be studied from the chosen

Neighbourhoods/communities; and

Stage 4: Selection of household respondents in the households to be studied, preferably heads of households, since they are usually the most knowledgeable about residential attributes

To achieve a representative sample of households in each neighbourhood, Yamane (1965) formula (given below) was applied.

$n=\frac{N}{1+N(\theta)^{2}}$

Where $\mathbf{n}$ is the sample size, $\mathbf{N}$ is the population size, and $\mathbf{e}$ is the level of precision (here set at $10 \%$ ).

Following determination of the sample size, the systematic sampling method (Kish, 1965) was used to select the households to be questioned from the ordered list of population elements). 
Table 1: Sampling Details

\begin{tabular}{|l|l|c|c|c|}
\hline \multicolumn{1}{|c|}{ Name of Stratum } & $\begin{array}{c}\text { Name of Neighbourhood/ } \\
\text { Community }\end{array}$ & $\begin{array}{c}\text { Total No. of } \\
\text { Buildings }\end{array}$ & $\begin{array}{c}\text { Total of No. } \\
\text { Households (N) }\end{array}$ & \begin{tabular}{c} 
Sample Size * \\
\hline
\end{tabular} \\
\hline \multirow{2}{*}{ Informal Settlements } & Marine Base Water Front & 770 & 3,850 & 98 \\
\cline { 2 - 5 } & Afikpo Water Front & 185 & 94 & $\mathbf{5 , 3 3 8}$ \\
\hline Total & $\mathbf{9 5 5}$ & $\mathbf{1 9 2}$ & 94 \\
\hline
\end{tabular}

*Using the Taro Yamane Formula @ 10\% Level of Precision

This study adopted a passive-observational research design. Passive-observational research designs pertain to studies where there has been no prior "treatmemt", intervention, or manipulation of subjects. The data was collected through a household questionnaire and utilized univariate analysis. This study formed one index Subjective (Perceived) Neighbourhood Quality Index (SNQI), using subjective neighbourhood attributes.

\section{Findings Of The Study}

This section presents results of analyses carried out in the course of the study. One hundred and ninety-two (192) household questionnaires were administered and 191 retrieved, i.e. a response rate of $99.5 \%$. Analysis was therefore based on 191 households, representing $4 \%$ of the target population of households in the in two informal settlements.

\subsection{Neighbourhood Attributes}

Table 2 displays the existence or otherwise of selected neighbourhood attributes in the 2 component neighbourhoods of the informal settlements. The 7 selected attributes were:

i. Garbage on streets/ neighbourhood;

ii. Street lighting;

iii. Traffic congestion;

iv. Neighbourhood Vigilante Groups;

v. Neighbourhood Gangs;

vi. Periodic flooding; and

vii. Public transportation.

Table 2 reveals that garbage was found on the streets and neighbourhoods in the two neighbourhoods.( See Plate 2) This shows that the neighbourhoods are not very clean, so government should intensify effort in its environmental sanitation programme.

Table 2 also reveals that there were no street light in the neighbourhoods and pose a threat to security as hoodlums can hide in darkness to harm passersby. The study presents traffic situation in good light. It reveals that there was no traffic congestion in the neighbourhoods (see Table 2).

Table 2 reveals that there are no neighbourhood vigilante groups these areas. Table 2 further reveals that neighbourhood gangs exist in Marine - Base and Akikpo water front. This also pose security treat to residents and it is the collective effort of government and residents to ensure that neighbourhood gangs are completely eliminated. Table 2 further reveals that public transportation is available in Marine-Base except Afikpo water front. Table 2 also revealed that periodic flooding occur in all the neighbourhoods. Government and residents should intensify efforts to tackle the problem of flooding. Flooding in the city of Port Harcourt is caused mainly by blocked drains and construction of houses on natural drains due to unplanned development. 
Table 2: Existence/Non Existence of Selected Neighbourhood Attributes in the 2 Component Neighbourhoods of the Informal Settlements

\begin{tabular}{|c|c|c|c|c|c|c|c|c|}
\hline \multirow{2}{*}{$\begin{array}{l}\text { Stratu } \\
\text { m }\end{array}$} & \multirow{2}{*}{$\begin{array}{l}\text { Comm } \\
\text { unities }\end{array}$} & \multicolumn{7}{|c|}{ Existence/Non-Existence of Selected Neighbourhood Attributes } \\
\hline & & $\begin{array}{l}\text { Garbag } \\
\text { e on } \\
\text { Street/ } \\
\text { Neighb } \\
\text { ourhoo } \\
\text { d }\end{array}$ & $\begin{array}{c}\text { Street } \\
\text { Lighti } \\
\text { ng }\end{array}$ & $\begin{array}{l}\text { Traffic } \\
\text { congestio } \\
n\end{array}$ & $\begin{array}{l}\text { Neighbo } \\
\text { urhood } \\
\text { Vigilante } \\
\text { groups }\end{array}$ & $\begin{array}{c}\text { Neighbour } \\
\text { hood } \\
\text { Gangs }\end{array}$ & $\begin{array}{l}\text { Periodic } \\
\text { Flooding }\end{array}$ & $\begin{array}{l}\text { Public } \\
\text { Transp } \\
\text { ortatio } \\
\text { n }\end{array}$ \\
\hline \multirow{2}{*}{$\begin{array}{c}4 \\
\text { (Squatt } \\
\text { er } \\
\text { Settle } \\
\text { ments) }\end{array}$} & $\begin{array}{l}\text { Marine } \\
\text { Base } \\
\text { Waterfr } \\
\text { ont }\end{array}$ & $\bullet$ & 0 & $\circ$ & $\circ$ & $\bullet$ & $\bullet$ & $\bullet$ \\
\hline & $\begin{array}{l}\text { Afikpo } \\
\text { Waterfr } \\
\text { ont }\end{array}$ & $\bullet$ & 0 & 0 & o & $\bullet$ & $\bullet$ & o \\
\hline
\end{tabular}

(Source: Authors' Field Survey, 2011)

\subsection{Neighbourhood Services}

Table 3 shows that there are no public primary schools in Marine Base and Afikpo Waterfront Settlements. This is expected since these are informal settlements. A similar pattern is also reflected in the provision of public secondary schools.

Table 3: Distribution of Neighbourhood Services in the 2 Study Neighbourhoods

\begin{tabular}{|l|c|c|}
\hline \multicolumn{1}{|c|}{ Services } & $\begin{array}{c}\text { Marine } \\
\text { Base }\end{array}$ & $\begin{array}{c}\text { Afikpo } \\
\text { Waterfront }\end{array}$ \\
\hline Primary Schools (Public) & 0 & 0 \\
\hline Public Secondary School & 0 & 0 \\
\hline Private Recreational Areas & 0 & 0 \\
\hline Public Recreational Areas & 0 & 0 \\
\hline Traditional Markets & 1 & 0 \\
\hline Super Markets & 0 & $5+$ \\
\hline Retail Shops & $5+$ & 0 \\
\hline Hospital/Clinics & 0 & 0 \\
\hline Fire Stations & 0 & 0 \\
\hline Police Stations & 1 & \\
\hline
\end{tabular}

(Source: Authors' Field Survey, 2011)

Table 3 also reveals the paucity of recreational facilities in the neighborhoods. Each neighbourhood had a traditional (local) market. There were no supermarkets in the informal settlements. Over 5 retail shops existed in each neighbourhood; but hospitals and clinics were not present in the 2 neighbourhoods. Marine-Base Waterfront had a police station, except Afikpo Waterfront Settlement, suggesting inadequacy of police protection in the informal settlements.

\subsection{Residents' Perceptions of Selected Neighbourhood Attributes in the Two (2) Neighbourhoods in the Informal Settlements.}

Residents of the two (2) neighbourhoods were also asked to indicate their level of agreement or disagreement with statements describing selected attributes of their neighbourhoods. Table 4 shows these results. Most of the respondents $(56.5 \%)$ disagree that elementary schools are within easy reach from their dwellings in these areas. Slightly less than a quarter of respondents in the informal settlements strongly disagree that there is a hospital or clinic within walking distance from their dwellings while $60 \%$ of the respondents agree that hospital or clinic is within walking distance from their dwellings. Also $11 \%$ of the respondents were neutral.

Most of the respondents see their neighbourhoods in a positive light with regards to the statement that this neighbourhood is well provided with shopping facilities, such as traditional markets, grocery stores and 
supermarkets representing $70.2 \%$. Slightly less than half $(48.6 \%)$ of the residents in the informal settlements see their neighbourhoods in a positive light with regards to police station within easy reach from their dwelling. This implies that police protection is inadequate in these neighbourhoods.

Only $7.8 \%$ of residents in the informal settlements agree that their neighbourhoods are clean while $75.9 \%$ disagree to the cleanliness of their neighbourhoods. However $16.2 \%$ in these areas were neutral to this statement (Table 4). The study further reveals that $84.3 \%$ of the residents in the informal settlements see their neighbourhoods in a negative light with regards to street maintenance while only $6.2 \%$ of residents in these areas in Port Harcourt said the streets are well maintained. This is expected since there are no roads in these areas. The study also shows that $48.7 \%$ of the respondents agree that their neighbourhood is a safe place to live in across the informal settlements (See Table 4). The study further revealed that $57.1 \%$ of the residents agree that their neighbours are friendly.

Table 4: Perception of Selected Neighbourhood Attributes in the two(2) Informal settlements.

\begin{tabular}{|c|c|c|}
\hline \multirow[t]{2}{*}{ Neighbourhood Attributes } & \multicolumn{2}{|c|}{ Informal Settlements } \\
\hline & \multicolumn{2}{|l|}{$\begin{array}{l}\mathbf{N} \\
\%\end{array}$} \\
\hline \multicolumn{3}{|c|}{ Elementary Schools are within easy reach from my dwelling } \\
\hline 1.0 Disagree Strongly & 64 & 33.5 \\
\hline 2.0 Disagree Somewhat & 44 & 23.0 \\
\hline 3.0 Neither Agree Nor Disagree & 12 & 6.3 \\
\hline 4.0 Agree Somewhat & 54 & 28.3 \\
\hline 5.0 Agree Strongly & 11 & 5.8 \\
\hline Missing Data & 6 & \\
\hline & \multicolumn{2}{|c|}{3.1} \\
\hline Total & 191 & 100 \\
\hline \multicolumn{3}{|c|}{ There is a hospital/clinic within walking distance from my dwelling } \\
\hline 1.0 Disagree Strongly & 84 & 44.0 \\
\hline 2.0 Disagree Somewhat & 42 & 22.0 \\
\hline 3.0 Neither Agree Nor Disagree & 21 & 11.0 \\
\hline 4.0 Agree Somewhat & 39 & 20.4 \\
\hline 5.0 Agree Strongly & 5 & 2.6 \\
\hline Missing Data & 0 & 0 \\
\hline Total & 191 & 100 \\
\hline \multicolumn{3}{|c|}{$\begin{array}{l}\text { This neighborhood is well-provided with shopping facilities, such as traditional } \\
\text { markets, grocery stores, and supermarkets }\end{array}$} \\
\hline 1.0 Disagree Strongly & 22 & 11.5 \\
\hline 2.0 Disagree Somewhat & 7 & 3.7 \\
\hline 3.0 Neither Agree Nor Disagree & 28 & 14.7 \\
\hline 4.0 Agree Somewhat & 75 & 39.3 \\
\hline 5.0 Agree Strongly & 59 & 30.9 \\
\hline Missing Data & 0 & 0 \\
\hline Total & 191 & 100 \\
\hline \multicolumn{3}{|c|}{ There is a police station in this neighborhood within easy reach from my dwelling } \\
\hline 1.0 Disagree Strongly & 45 & 23.6 \\
\hline 2.0 Disagree Somewhat & 24 & 12.6 \\
\hline 3.0 Neither Agree Nor Disagree & 29 & 15.2 \\
\hline 4.0 Agree Somewhat & 53 & 27.7 \\
\hline 5.0 Agree Strongly & 40 & 20.9 \\
\hline Missing Data & 0 & 0 \\
\hline Total & 191 & 100 \\
\hline \multicolumn{3}{|l|}{ This neighbourhood is clean. } \\
\hline 1.0 Disagree Strongly & 91 & 47.6 \\
\hline 2.0 Disagree Somewhat & 54 & 28.3 \\
\hline 3.0 Neither Agree Nor Disagree & 31 & 16.2 \\
\hline 4.0 Agree Somewhat & 13 & 6.8 \\
\hline 5.0 Agree Strongly & 2 & 1.0 \\
\hline Missing Data & 0 & 0 \\
\hline Total & 191 & 100 \\
\hline \multicolumn{3}{|c|}{ The streets in this neighbourhood are well-maintained } \\
\hline 1.0 Disagree Strongly & 103 & 53.9 \\
\hline 2.0 Disagree Somewhat & 58 & 30.4 \\
\hline 3.0 Neither Agree Nor Disagree & 16 & 8.4 \\
\hline
\end{tabular}




\begin{tabular}{|l|lr|}
\hline $4.0 \quad$ Agree Somewhat & 10 & 5.2 \\
$5.0 \quad$ Agree Strongly & 2 & 1.0 \\
Missing Data & 2 & 1.0 \\
\hline Total & $\mathbf{1 9 1}$ & $\mathbf{1 0 0}$ \\
\hline The people around here are friendly & 38 & 19.9 \\
\hline $1.0 \quad$ Disagree Strongly & 12 & 6.3 \\
$2.0 \quad$ Disagree Somewhat & 32 & 16.8 \\
3.0 Neither Agree Nor Disagree & 85 & 44.5 \\
$4.0 \quad$ Agree Somewhat & 24 & 12.6 \\
$5.0 \quad$ Agree Strongly & 0 & 0 \\
Missing Data & $\mathbf{1 9 1}$ & $\mathbf{1 0 0}$ \\
\hline Total & \multicolumn{2}{|c|}{} \\
\hline This neighbourhood is a safe area to live in & 53 & 27.7 \\
\hline $1.0 \quad$ Disagree Strongly & 19 & 9.9 \\
$2.0 \quad$ Disagree Somewhat & 18 & 9.4 \\
$3.0 \quad$ Neither Agree Nor Disagree & 67 & 35.1 \\
$4.0 \quad$ Agree Somewhat & 26 & 13.6 \\
$5.0 \quad$ Agree Strongly & 8 & 4.2 \\
Missing Data & $\mathbf{1 9 1}$ & $\mathbf{1 0 0}$ \\
\hline Total & $\mathbf{4}$ & \\
\hline Mode & $2011)$ &
\end{tabular}

(Source: Author's Field Survey, 2011)

\subsection{Residents' Evaluation of Selected Neighbourhood Attributes in the Informal Settlements}

The residents were asked to indicate whether certain attributes of their neighbourhood environment were too few, about right or too many. The responses are presented below. Table 5 shows that $61.3 \%$ of the respondents stated that elementary schools were too in the city while $33.0 \%$ said that primary schools were too few.

Table 6 reveals that $74.3 \%$ of the respondents said hospitals/clinics were too few across the city while $25.2 \%$ of the respondents said that the hospitals/clinics were about right. The modal distribution reveals that police stations were too few in the city. Most of the residents (78.5\%) in the city said that the city council never picks up waste while $15.7 \%$ of the residents said that the city council pick up waste occasionally (See Table 5 and Plate .2). This implies that the city council has not fully lived up to its responsibility, so should improve on it services in this regards. Plate 1and 2 show case the neighbourhood environmental conditions in the informal areas. Most respondents $(78.5 \%)$ stated that it is fairly easy to get to shopping facilities to purchase their daily needs (see Table 5). Table 5 further shows that $19.9 \%$ of the respondents reported that the condition of streets allow people and vehicles to move about with no difficulty at all while $78.6 \%$ of the respondents reported that the conditions of streets makes it difficult for people and vehicles to move about.

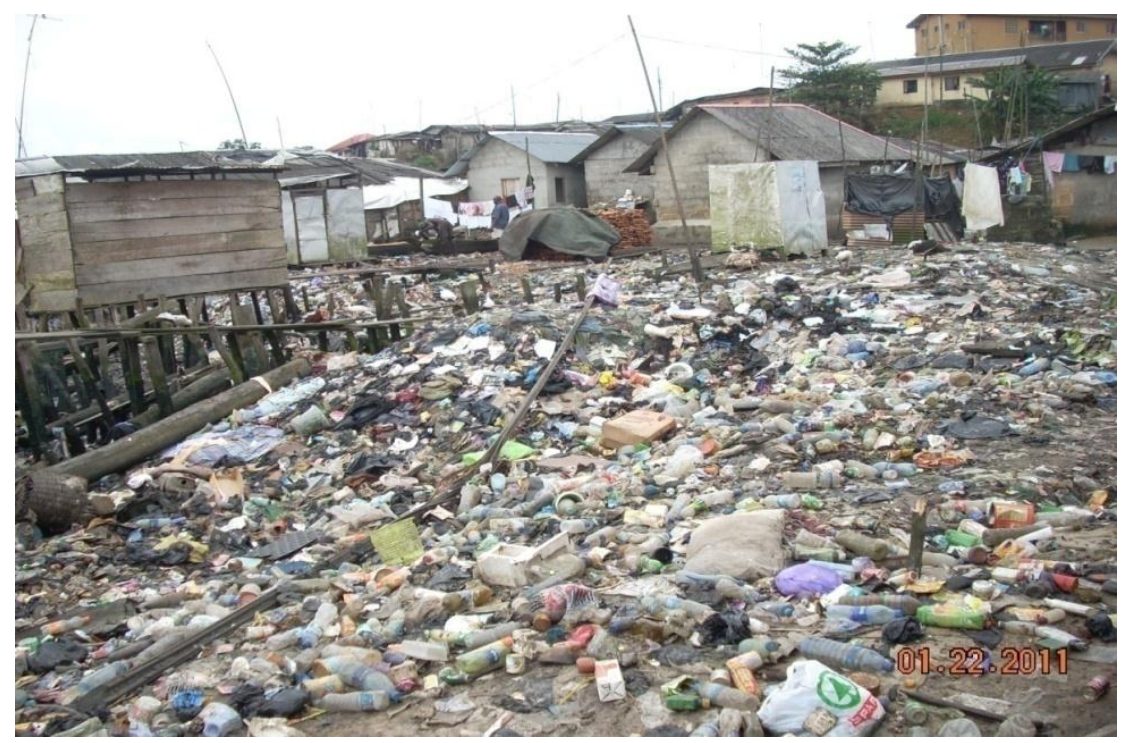

Plate 2: A Waste Dump at Afikpo Water Front.

(Source: Authors' Field Survey, 2011) 
Table 5: Evaluation of Selected Neighbourhood Attributes in the Informal Settlement

\begin{tabular}{|c|c|c|}
\hline Neighbourhood Attributes & \multicolumn{2}{|c|}{ Informal Settlements } \\
\hline & $\mathbf{N}$ & $\%$ \\
\hline \multicolumn{3}{|c|}{$\begin{array}{l}\text { Would you say that there are too few elementary schools in this neighborhood, too many, or } \\
\text { is the number about right }\end{array}$} \\
\hline 1. Too Few & 117 & 61.3 \\
\hline 2. About Right & 63 & 33.0 \\
\hline 3. Too Many & 6 & 3.1 \\
\hline 4. Missing Data & 5 & 2.6 \\
\hline Total & 191 & 100 \\
\hline \multicolumn{3}{|c|}{$\begin{array}{l}\text { Considering the location of shopping facilities in this neighborhood, do you think that it is } \\
\text { very difficult to get to them for the purchase of your daily needs, rather difficult neither } \\
\text { difficult nor easy, fairly easy or very easy? }\end{array}$} \\
\hline 1. Very Difficulty & 5 & 2.6 \\
\hline 2. Rather Difficult & 14 & 7.3 \\
\hline 3. Neither Difficult Nor Easy & 20 & 10.5 \\
\hline 4. Fairly Easy & 103 & 53.9 \\
\hline 5. Very Easy & 47 & 24.6 \\
\hline 6. Missing Data & 2 & 1.0 \\
\hline Total & 191 & 100 \\
\hline \multicolumn{3}{|c|}{$\begin{array}{l}\text { In your opinion, are there too few hospitals/clinics serving this neighborhood, too many. Or } \\
\text { is the number about right }\end{array}$} \\
\hline 1. Too Few & 142 & 74.3 \\
\hline 2. About Right & 48 & 25.2 \\
\hline 3. Too Many & 0 & 0 \\
\hline 4. Missing Data & 1 & .5 \\
\hline Total & 191 & 100 \\
\hline \multicolumn{3}{|c|}{$\begin{array}{l}\text { Do you think that there are too few police stations, too many, or that the number is about } \\
\text { right to provide the services necessary for safety here? }\end{array}$} \\
\hline 1. Too Few & 117 & 61.3 \\
\hline 2. About Right & 72 & 37.7 \\
\hline 3. Too Many & 0 & 0 \\
\hline 4. Missing Data & 2 & 1.0 \\
\hline Total & 191 & 100 \\
\hline \multicolumn{3}{|c|}{$\begin{array}{l}\text { Does the city council pick up the garbage in this neighbourhood very often, often, } \\
\text { occasionally, or never? }\end{array}$} \\
\hline 1. Never & 150 & 78.5 \\
\hline 2. Occasionally & 30 & 15.7 \\
\hline 3. Often & 0 & 0 \\
\hline 4. Very Often & 4 & 2.1 \\
\hline 5. Missing Data & 7 & 3.7 \\
\hline Total & 191 & 100 \\
\hline \multicolumn{3}{|c|}{$\begin{array}{l}\text { In your opinion, does the condition of streets in this neighborhood allow people and vehicles } \\
\text { to move about with great difficulty, with some difficulty, or with no difficulty at all }\end{array}$} \\
\hline 1. With Great Difficulty & 105 & 55.0 \\
\hline 2. With Some Difficulty & 45 & 23.6 \\
\hline 3. With No Difficulty at all & 38 & 19.9 \\
\hline 4. Missing Data & 3 & 1.6 \\
\hline Total & 191 & 100 \\
\hline
\end{tabular}

(Source: Author's Field Survey, 2011)

\subsection{Other Neighbourhood Attributes}

Table 7 reveals that the main source of noise across the neighbourhoods is from electric generators with a percentage of $48.2 \%$. This is not surprising as the public supply of power is unreliable. This is closely followed by noise from sources in the neighbourhood. The study areas are free from noise from industries as revealed in Table 6. Transportation for public use is in form of Combi buses and taxis by individual small operators. They are unregulated and in poor condition generally. However, most residents use these taxis and buses as means of transportation in the city. The study futher reveals that most residents buy water from owners of private water boreholes. Table 6 also reveals that $63 \%$ of the respondents affirm that the electricity supply in a day on the average is between 3-8 hours. 
Table 6 : Other Neighbourhood Attributes in the Informal Settlements

\begin{tabular}{|c|c|c|}
\hline \multirow[t]{2}{*}{ Neighbourhood Attributes } & \multicolumn{2}{|c|}{ Informal Settlement } \\
\hline & $\mathbf{N}$ & $\%$ \\
\hline \multicolumn{3}{|l|}{ Sources of noise } \\
\hline 1. Noise from automobiles & 18 & 9.4 \\
\hline 2. Noise from electric generators & 94 & 49.2 \\
\hline 3. Noise from industry & 0 & 0 \\
\hline 4. Others (specify) & 60 & 31.4 \\
\hline 5. Missing Data & 19 & \\
\hline & & 9.9 \\
\hline Total & 191 & 100 \\
\hline Mode & 2 & \\
\hline \multicolumn{3}{|l|}{ Means of transportation by household } \\
\hline 1. Public transportation & 60 & 31.4 \\
\hline 2. Taxi/buses & 110 & 57.6 \\
\hline 3. Private car & 9 & 4.7 \\
\hline 4. Missing Data & 12 & 6.3 \\
\hline Total & 191 & 100 \\
\hline \multicolumn{3}{|c|}{ Hours of Electricity Supply in a Day on The Average } \\
\hline $10-2$ Hours & 0 & 0 \\
\hline $2.3-4$ Hours & 25 & 13.1 \\
\hline 3 5-6 Hours & 40 & 26.9 \\
\hline $4 \quad 7-8$ Hours & 44 & 23.0 \\
\hline 5 .9-10 Hours & 27 & 14.1 \\
\hline 6. 11-12 Hours & 12 & 6.3 \\
\hline 7. 13-14 Hours & 7 & 3.7 \\
\hline 8. Above 14 Hours & 28 & 14.7 \\
\hline 9. Missing Data & 8 & 4.2 \\
\hline Total & 191. & 100 \\
\hline \multicolumn{3}{|l|}{ Potable Water Supply } \\
\hline 1. Pipe borne water from public mains & 15 & 7.9 \\
\hline 2. Pipe borne water from borehole. & 19 & 9.9 \\
\hline 3. Well. & 0 & 0 \\
\hline 4. Buy from borehole. & 155 & 81.2 \\
\hline 5. Missing data. & 2 & 1.0 \\
\hline Total & 191 & 100 \\
\hline
\end{tabular}

(Source: Author's Field Survey, 2011)

\subsection{Neighbourhood Quality Index}

Table 7 reveals that $52.9 \%$ of residents in the informal neighbourhoods perceived their neighbourhood to be of medium quality while $30.4 \%$ and $2.1 \%$ perceived it to be of low and high quality respectively.

Table 7: Neighbourhood Quality Index in the Informal Settlements

\begin{tabular}{|l|l|r|}
\hline \multicolumn{1}{|c|}{ Quality Informal Settlements } & $\mathrm{N}$ \\
\hline \multicolumn{1}{|c|}{} & \multicolumn{1}{|c|}{} \\
\hline Perceived Neighbourhood Quality in the Informal settlements & \\
\hline Low (1) & 58 & 30.4 \\
\hline Medium (2) & 101 & 52.9 \\
\hline High (3) & 4 & 2.1 \\
\hline Missing & 28 & 14.7 \\
\hline Total & $\mathbf{1 9 1}$ & $\mathbf{1 0 0}$ \\
\hline
\end{tabular}

(Source: Authors' Field Survey, 2011)

\subsection{Perceived Residential Quality of Life}

Table 8 captures the perception of residential quality of life in the study area with $50.3 \%$ of respondents reporting a negative quality. Specifically, $28.8 \%$ of the residents in the informal settlements were unhappy with their neighbourhood conditions while $8.4 \%$ perceived their residential environment as terrible. Only $15.7 \%$ of residents were pleased with their residential environment.

Table 9 also shows that most residents believed that employment will improve their residential quality of life and this is closely followed by better housing and improved sanitation. This implies that generation of 
An Assessment of Residential Quality of Life in Informal Settlements in Port Harcourt Municipality

employment opportunities, improved housing and sanitation important in improving urban residential quality of life in the informal settlements.

Table 8: Perceived Residential Quality of Life of the Informal Settlements

\begin{tabular}{|l|lr|}
\hline Perceived Residential Quality of Life as a whole & Informal Settlements & $\%$ \\
\hline 1.Terrible & $\mathrm{N}$ & 8.4 \\
2.Unhappy & 16 & 28.8 \\
3.Mostly dissatisfied & 55 & 13.1 \\
4.Mixed & 25 & 9.9 \\
5.Mostly satisfied & 19 & 14.1 \\
6.Pleased & 27 & 15.7 \\
7.Delighted & 30 & 7.9 \\
8.Missing data & 15 & 2.1 \\
\hline Total & 4 & $\mathbf{1 0 0}$ \\
\hline
\end{tabular}

(Source: Authors' Field Survey, 2011)

\section{Discussion Of Findings}

\subsection{Conditions of the Residential Environment}

Only the neighbourhood level of the residential environment was examined in this study.

The study reveals that garbage existed in the two neighbourhoods. This shows that neighbourhoods were not very clean and the government should intensify effort to clean the environment through its monthly environmental sanitation programme and daily collection of waste should be improved.

The study also reveals that there was no street lighting in the neighbourhoods. This is a serious problem and with the rising incidence of crime poses security threats in the neighbourhoods.

The study further reveals that neighbourhood gangs existed Marine Base and Afikpo Water Front. It is pertinent to explain that Marine Base and Afikpo Water Front are marginal settlements on the foreshores of the city. The findings are similar to those of Pacione (2003) who studied the nature and extent of fear of crime among male and female residents of a deprived social housing estate on the edge of Glasgow, and used the information to identify the geography of fear within the area. His research revealed that for both males and females crime was regarded as the second most serious problem in the area. His research further revealed that for most young males the high risk of assault was an accepted part of their lifestyle and living environment and fear of sexual assault for young females. Respondents according to him accepted that they were 'fair game' and an automatic target for local gangs. This is certainly true in the informal or squatter settlements.

The study also reveals that periodic flooding occurred in the two neighbourhoods. Most of the flooding is caused by blocked drains and construction of houses on natural drains. Educating the masses on waste management and good sense of environmental management will tackle the problem of periodic flooding to some extent. Control of development on natural drains and proper planning will also contribute to tackling the flood problem.

The study reveals that transportation for public use was readily available to the public, but it was provided by small scale operators in the private sector. Afikpo and Marine Base water front are slum settlements without proper street systems. Most residents affirmed that there were no drains. This is a critical issue as it can contribute to flooding during the rainy season and it is also a health challenge.

The study also reveals another unbearable problem which was noise pollution and this was mainly from private generators widely used for electricity generation as a result of irregularity in electricity supply from the Power Holding Company of Nigeria (PHCN). This study also reveals that the average power supply across the neighbourhoods ranged from just 3 to 8 hours per day. Interestingly, Marans (1979) in his study also found that conditions which were bothersome to the greatest number of neighbourhood residents were noise, heavy traffic, crime, litter and poorly maintained streets.

This is the reality in the municipality and requires concerted intervention by government to ameliorate the situation. The incessant power cuts have increased noise pollution in our neighbourhoods and this also poses health risks as a result of the noise and air pollution.

The study also reveals that there were no primary and secondary schools in the two informal settlements studied. The study also reveals that there is only one fire station in the whole of Port Harcourt municipality. This is grossly inadequate. More fire stations are needed in the study area. This gross inadequacy of fire stations has led to destruction of buildings by fire in recent times in the city.

The study reveals that shopping facilities such as retail shops existed in the neighbourhoods. Hospitals and clinics were not available in two neighbourhoods -- Marine Base and Afikpo Water Front. Marans (1979) also 
reported such inadequacies in public services provision of health care, shopping and transportation facilities in his study of the determinants of neighbourhood quality.

One major finding of this study was the current situation of water supply by the government in the city as a whole. In the informal settlements, most residents bought water from owners of private boreholes while only a few of the residents had pipe-borne water from government. This is a critical issue and shows that government provision of this basic and important service is virtually nonexistent. This is in line with findings from previous studies. Wokekoro (2005) also established that the main source of water supply was the private borehole in Port Harcourt. This shows that the water supply situation has not improved in the city. In order to ensure public health and safety there must be adequate supply of water. It is unlikely that Target 10 of the Millennium Development Goal (MDG) 7 will be achieved by the year 2015. MDG 7 urged governments and policy makers to "halve the proportion of people without access to safe drinking water and basic sanitation by 2015". It also implies that the primary goal of successive National Housing Policies which is to ensure that all Nigerians own or have access to decent, safe and sanitary housing accommodation of affordable cost with secure tenure has not been achieved. These conditions were also observed by Ogionwo (1979) and Izeogu (1989), which shows that housing condition, has not improved.

Another salient finding of the study pertains to household waste collection and disposal. $78.5 \%$ of respondents agree that their household waste was never collected by the municipal authority. Waste collection and disposal was mostly by private refuse vendors using locally fabricated metal carts, Waste was dumped into the creeks as shown in Plate 2. The dumping of refuse into creeks, drains and roads is a major cause of water pollution, flooding and insanitary environment. The blocked drains have become breeding grounds for mosquitoes and subsequently affect the health of residents.

\subsection{Residents' Perception of the Residential Environment}

Most respondents disagreed that elementary (primary) schools and police stations were within easy reach of their dwellings. This shows that physical access to primary schools and police posts was inadequate in the informal neighbourhoods

Most respondents agreed that their neighbourhoods were well provided with shopping facilities such as local markets and retail shopping outlets. These facilities are private business enterprises engaged in for economic survival. A further finding was that $66 \%$ of respondents in the two neighbourhoods disagreed that there was a hospital or health clinic within walking distance of their dwelling. Most respondents (74.3\%) across the neighbourhoods also affirmed that hospitals/clinics were too few. Within the municipality there are five public health care facilities, comprising two Specialist hospitals, and three primary health centres. The rest are private outfits.

One major finding of the study was that most residents across the neighbourhoods rated maintenance of streets, recreational areas, public schools, safety of lives and properties, residential planning, provision of housing for the poor, hospitals/clinics, fire stations, police stations, waste collection and disposal as inadequate while most respondents rated public transport and shopping facilities as generally adequate. The finding of this study is similar to that of Wokekoro (2005) in terms of street maintenance. Wokekoro (2005) observed streets with potholes (35.9\%) which showed lack of street maintenance.

\subsection{Perceived Residential Quality Of Life}

The study reveals that $28.8 \%$ of the residents were unhappy with their residential environment while $15.7 \%$ were pleased with their residential environment. The study further reveals that most residents believe that employment, provision of basic amenities and housing would improve their residential quality of life. Interestingly, most respondents were low-income earners in these neighbourhoods and fell within the low socio economic status (SES) bracket

\subsection{Conclusions}

\section{Conclusions And Recommendations}

In this study the residential quality of life in Port Harcourt was examined. The paper examined one aspect of the residential environment namely: the neighbourhood. Based on the study most residents across the neighbourhoods rated maintenance of streets, recreational areas, safety of lives and properties, residential planning, provision of housing for the poor, hospitals/clinics, fire stations, police stations, waste collection and disposal inadequate. The study further reveals that most residents rated public schools, transportation and shopping facilities very adequate. 
An Assessment of Residential Quality of Life in Informal Settlements in Port Harcourt Municipality

The study concludes that most residents were not satisfied about their residential conditions such as electricity supply, water supply and waste collection and disposal. The study further revealed that $28.8 \%$ of the residents across the neighbourhoods were unhappy with their residential quality of life and $52.9 \%$ of the residents perceived their neighbourhoods to be of medium quality. A key conclusion of the study was that the improvement of neighbourhood residential conditions as perceived by the residents was important in raising residential quality of life, and that in the provision of public infrastructure and services, the perceptions and preferences of the beneficiaries/target population must be seriously taken into account to achieve user satisfaction.

\subsection{Recommendations}

\subsubsection{Maintenance of Roads and Streets}

The study has shown that most respondents were not satisfied with street maintenance in their neighborhoods. Government should ensure the proper maintenance of roads and streets, taking advantage of funds available in the National Urban Development Bank, assistance from international development agencies and through private-public-partnership (PPP) arrangements.

\subsubsection{Safety of Lives and Property}

The study reveals that virtually in all the neighbourhoods there was no street lighting. This is a security issue and this essential service should be provided by government. The study further reveals that most people in some neighbourhoods were not satisfied with the level of police protection. This is a responsibility of government and should be adequately addressed. Neighbourhood vigilante groups should be encouraged to work in collaboration with the police also in securing lives and properties since security is everybody's business.

\subsubsection{Neighbourhood Services}

The study also reveals that electricity supply and water supply were inadequate. Furthermore it was found that the main source of noise pollution was from the use of electric generators brought about by incessant power cuts in the city. People were very dissatisfied with electricity supply. Regular power supply could be achieved through public-private partnership and current privatization process embarked upon by the Federal Government. Government provision of water supply was virtually nonexistent. Government should partner with the private sector to provide this essential service to the populace. Government should also look into other forms of electricity generation such as solar power, biomass, wind, tidal energy which is in abundant supply in the country.

The study also found that people were not satisfied with waste collection and disposal. Waste collection should be done on regular basis. Public-Private partnership should also be adopted. The current practice of waste disposal into drains by the residents should be discouraged and appropriate measures should be put in place to punish perpetrators. The monthly environmental sanitation exercise should be used as a public enlightenment tool; during the exercise, the practice of removing waste from drains and putting same on the roadsides should be discouraged.

Finally, the study found that residents believed that residential quality of life would be improved through the provision of basic amenities, good housing and proper sanitation. These basic needs and services should be adequately put in place through properly designed policies and massive education.

\section{References}

[1]. Andrews, F. M. (1980). Subjective Social Indicators, Objective Social Indicators, and Social Accounting Systems. Survey Research Centre, The University of Michigan, Ann Arbor, USA.

[2]. Camfield, L. (2005). Researching Quality of Life in Developing Countries.ESRC News Letter Vol. 3 No.1.www.welldev.org.uk Accessed 21/3/2009

[3]. Coker, A.O, Awokola, O.S., Olomolaiye, P. O., and Booth, C. A. (2007). Challenges of urban Housing Quality and its Associations with Neighbourhood Environments: insights and experiences of Ibadan City,Nigeria.Chartered Institute of Environmental Health www.cieh.org Accessed 16/ 7/ 09

[4]. Discoli, Rosenfeld, Juan,s., Martini, Barbero, Ferreyro,and Dicroce (2006).“ Urban Integration and Disintegration Forces: The habitants/Users Perception in an Urban life Quality Model for the Surroundings of LaPlata, Buenos Aires, Argentina."A paper presented at the $42^{\text {nd }}$ International Society of City and Regional Planners ( IsoCARP) Congress, 2006.

[5]. Giannias, D. A (1996).Quality of Life in Southern Ontario. Department of Economics, University of Crete, Athens Greece. www. findarticles.com Accessed 15/5/11

[6]. Guhathakurta, S. And Sadalla, E. (Undated) Modeling the Impact of Environment on Quality of Life. Accessed 11/7/2008.

[7]. Hall,L.J., Madrigal,R. and Robalino, J.(2008). "Quality of Life in Urban Neighborhoods in Costa Rica", Inter-American Development Bank, Latin American Research Network, Research Network Working Paper www.iadb.org/res/publications/pubfiles\#R-563. Accessed 16/7/09

[8]. Jongudomkarn, D. and Camfield, L.(2005). "Exploring The Quality of Life ofPeople in North Eastern And southern Thailand" WeD Working Paper11www.welldev.org.uk Accessed 16/7/09

[9]. Kish, L. (1965). Survey Sampling. John Willey and Sons Inc. New York.643pp. 
[10]. Lotfi, S. and Solaimani, k.(2009). "An assessment of Urban Quality of Life by Using Analytic Hierarchy Process Approach(Case study: Comparative Study of Quality of Life in the North of Iran)" Journal of Social Sciences 5(2):123-133.

[11]. Marans, R. W. (!979). The Determinants of Neighbourhood Quality: An Analysis of the 1976 Annual Housing Survey. A Report Prepared for the U.S. Department of Housing and Urban Development, Office of Policy Development and Research.

[12]. Mchi, A.A. (1997).“Assessing Residential Environmental Quality withinSelected Resid ential Areas of Port Harcourt.” Unpublished B Tech Project. Department of Urban \& Regional Planning, Rivers State University Science \& Technology, Port Harcourt.

[13]. Melnick,D., McNeely, J. , Navarro,Y.K., Schmidt-Traub, G. and Sears, R. R.(2005).Environment and Human Wellbeing: a Practical Strategy. UN Millenium Project. Earthscan, London. 133pp.

[14]. Obinna, V.C., Owei, O. B. and Mark, E.O.(2010). "Informal Settlements of Port Harcourt and Potentials For Planned City Expansion." Environmental Research Journal Vol.4, No. 3, pp 222-228.

[15]. Ogionwo, W. (1979). A Social Survey of Port Harcourt. Heinemann Educational Books (Nig.) Ltd, Enugu. 273 Pp.

[16]. Oyesiku, O. K. (2009). City Liveability: Implications and Challenges. A Lead Paper Presented at the Commonwealth Association of Planners, West Africa Workshop on Planning For Liveable Human Settlement: The West African Challenges. Lagos, Nigeria. $3^{\text {th }}-4^{\text {th }}$ November, 2009.

[17]. Pacione, M. (2003). "Urban Environmental Quality and Human Wellbeing—A Social Geographical Perspective." Landscape and Urban Planning 65. pp.19-30.

[18]. Salau, A. T. (1986). "Quality of life and city size: An exploratory study of Nigeria." Social Indicators Research Vol.18, No.2 pp.193-203

[19]. Senecal,G.(2002)."Urban Spaces and Quality of Life: Moving Beyond Normative Approaches" http://policyresearch.Gc.Ca/page.Asp?Pagenm=vsnl-art-06 Accessed 18/12/2002

[20]. Ugwuorah, A. N. (2002). The Relevance of the Urban and Regional Law (Decree. 88 of

[21]. 1992) to Environmental Management in Port Harcourt Metropolis." Unpublished M. Phil.

[22]. Thesis, Department of Environmental Management, Institute of Geosciences and Space

[23]. Technology, RSUST, Port Harcourt.

[24]. UNHSP(2008). The State of African Cities, A framework For Addressing Urban Challenges in Africa.UN Habitat. Nairobi, Kenya. 206pp.

[25]. WHO-IASSID WORK PLAN (2000). Quality of Life its Conceptualization Measurements

[26]. and Application. .A Consensus Document. The Special Interest Research Group on

[27]. Quality of Life. The International Association for the Scientific Study of Intellectual

[28]. Disabilities. www.beachcenter.org/boards/fullpublications Accessed 11/7/2008.

[29]. Wokekoro, E. and Owei, O.B.(2006). "Environmental Indicators of Derelict Housing in Nigerian Cities case Study of Port Harcourt, Rivers State." A Paper Presented at the International Conference on Infrastructure Development and the Environment (ICIDEN), Abuja Nigeria. September $10-15,2006$.

[30]. Yamane, T. (1967). Statistics, an Introductory Analysis $2^{\text {nd }}$ ed., Harper and Row, New York. 919pp 